\title{
High-solid anaerobic digestion of sewage sludge: achievements and perspectives
}

\author{
Ying Xu ${ }^{1}$, Hui Gong ${ }^{1}$, Xiaohu Dai $(\bowtie)^{1,2}$ \\ 1 State Key Laboratory of Pollution Control and Resource Reuse, School of Environmental Science and Engineering, \\ Tongji University, Shanghai 200092, China \\ 2 Shanghai Institute of Pollution Control and Ecological Security, Shanghai 200092, China
}

\begin{abstract}
H I G H L I G H T S
- High-solid anaerobic digestion (HS-AD) of sewage sludge (SS) is overviewed.

- Factors affecting process stability and performance in HS-AD of SS are revealed.

- HS effect and knowledge gaps of current research on the HS-AD of SS are identified.

- Future efforts on addressing knowledge gaps and improving HS-AD of SS are proposed.
\end{abstract}

\section{A R T I C L E I N F O}

\section{Article history:}

Received 3 July 2020

Revised 23 September 2020

Accepted 30 September 2020

Available online 4 November 2020

\section{Keywords:}

High-solid effect

Anaerobic fermentation

Methane production

Biodegradability

Sludge treatment

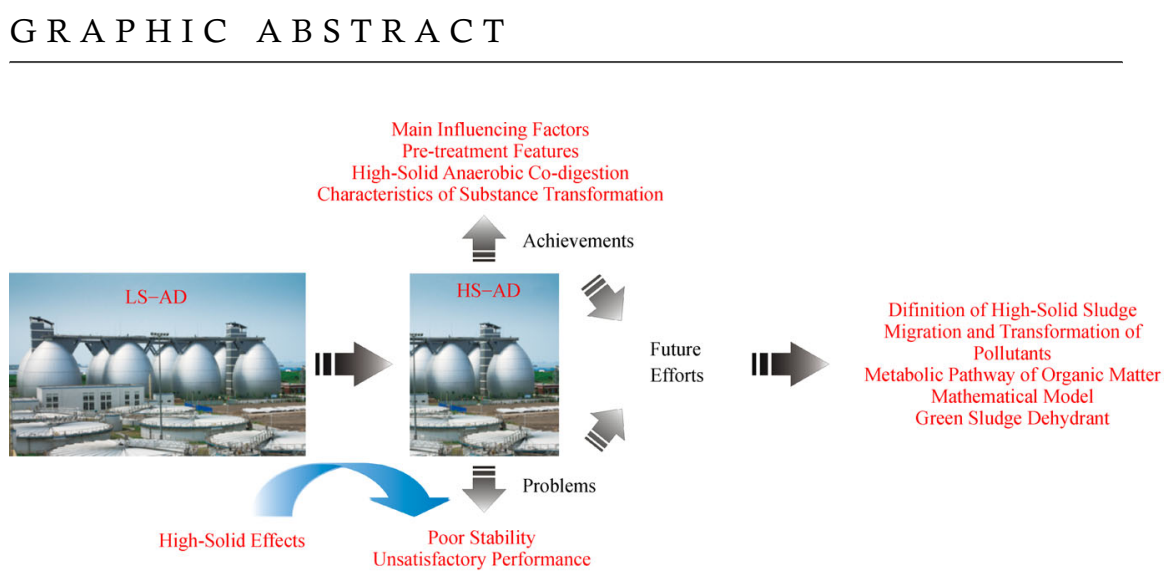

\begin{abstract}
A B S T R A C T
High-solid anaerobic digestion (HS-AD) has been applied extensively during the last few decades for treating various organic wastes, such as agricultural wastes, organic fractions of municipal solid wastes, and kitchen wastes. However, the application of HS-AD to the processing of sewage sludge (SS) remains limited, which is largely attributable to its poor process stability and performance. Extensive research has been conducted to attempt to surmount these limitations. In this review, the main factors affecting process stability and performance in the HS-AD of SS are comprehensively reviewed, and the improved methods in current use, such as HS sludge pre-treatment and anaerobic codigestion with other organic wastes, are summarised. Besides, this paper also discusses the characteristics of substance transformation in the HS-AD of SS with and without thermal pretreatment. Research has shown that the HS effect is due to the presence of high concentrations of substances that may inhibit the function of anaerobic microorganisms, and that it also results in poor mass transfer, a low diffusion coefficient, and high viscosity. Finally, knowledge gaps in the current research on HS-AD of SS are identified. Based on these, it proposes that future efforts should be devoted to standardising the definition of HS sludge, revealing the law of migration and transformation of pollutants, describing the metabolic pathways by which specific substances are degraded, and establishing accurate mathematical models. Moreover, developing green sludge dewatering agents, obtaining high value-added products, and revealing effects of the above two on HS-AD of SS can also be considered in future.
\end{abstract}

(C) The Author(s) 2020. This article is published with open access at link.springer.com and journal.hep. com.cn

\section{Introduction}

With the increasing global population and the growth of cities, the quantity of municipal wastewater has rapidly

$凶$ Corresponding author

E-mail: daixiaohu@tongji.edu.cn increased. Consequently, the production of sewage sludge (SS), a by-product of biological wastewater treatment, in wastewater treatment plants (WWTPs) has continuously increased in recent years (Xu and Dai, 2020). For example, by the end of 2019, SS production (defined as having an $80 \%$ moisture content) in China had exceeded 50.0 million tons/year, and it is predicted to exceed 65.0 million tons/ year between 2020 and 2025 (Geng et al. 2020). Notably, 
SS contains large concentrations of toxic, harmful and perishable pollutants (i.e., biological protein, polysaccharides, microbial cells, and its secretion etc.), which may cause great environmental harm if not properly treated. Anaerobic digestion (AD) is one of the most popular and promising methods of treating the sludge, because it can reduce the amount of sludge, kill pathogenic microorganisms, and recover the bio-energy such as methane at the same time.

The earliest application of $\mathrm{AD}$ is thought to have commenced in the $19^{\text {th }}$ century, and it has gradually become an accepted technology for the treatment of biodegradable organic wastes (McCarty, 2001). For example, between 1995 and 2010, approximately 150200 large-scale AD plants were established across Europe, with a capacity increase of 6 million tonnes of biomass annually (Fagbohungbe et al., 2015). In general, non-SS organic waste is categorised in terms of its total solids (TS) content, with low-solid AD (LS-AD) systems processing non-SS organic waste with a TS content $<15 \%$, and highsolid AD (HS-AD) systems processing non-SS organic waste with a TS content $>15 \%$ (Rapport et al., 2008; Li et al., 2011). As SS contains a large volume of water, conventional AD operates on SS with a low solid content (0.2\%-5\%), Zhang et al. (2015 and 2016) explored the influence of sludge TS content on $\mathrm{AD}$ and diffusion behaviour, and concluded that a TS content of $6 \%$ represented the boundary between the LS-AD and HSAD of SS. HS-AD systems have also been applied to treat non-SS solid organic materials, such as yard waste, food wastes, and organic fractions of municipal solid wastes (OFMSW) (Li et al., 2011). However, the use of LS-AD systems to treat SS is not always feasible in small-scale WWTPs, or if SS has a low organic-matter content, i.e., volatile solids (VS) $/ \mathrm{TS}<50 \%$. For example, the LS-AD of SS has not been well applied in China: up to 2019, only 70 of China's 5200 WWTPs incorporated LS-AD systems, and only 20 of these were operated routinely. The main reasons for this are poor management, economic limitations, and inadequate planning, as well as the characteristics of SS (i.e., low VS/TS) in China. Specifically, in many areas of China, the VS content of sludge has been found to be much lower (typically $<55 \%$ of TS) than that in developed countries (usually $>70 \%$ of TS) (Duan et al., 2016; Xu et al., 2020a). HS-AD may be a viable way to solve these problems, because this SS processing technique uses a smaller reactor volume, has lower energy requirements for heating, generates less wastewater, and has a higher volumetric biogas production rate than LSAD. Recently, SS dewatering has been developed to reduce SS volume, which enhances the HS-AD process. For example, Duan et al. (2012) proved the feasibility of HS$\mathrm{AD}$ of SS under mesophilic conditions by using dewatered SS (TS contents of 10\%, 15\% and 20\%), and also found that with a concentration of free ammonia-nitrogen
$($ FAN $)<600 \mathrm{mg} / \mathrm{L}$, the HS-AD of SS was satisfactorily stable. Moreover, they found that although methane production and VS reduction by the HS-AD of SS were similar to those by the LS-AD of SS, with the same solid retention time (SRT), a much higher volumetric methane production rate was achieved by the HS-AD system. Hidaka et al. (2013) also reported that the AD of SS containing $10 \%$ TS can be successfully achieved under mesophilic conditions, and highlighted that controlling total ammonia concentration renders the HS-AD of SS suitable for use in small facilities. These findings were further confirmed by Liao et al. (2014), who found that the HS-AD of SS significantly increased the volumetric biogas production rate and the treatment capability of digesters. These researchers also proposed that HS-AD offers an attractive option for treating dewatered sludge, which could provide a new direction for the anaerobic treatment of SS.

Figure 1 shows the annual numbers of publications on ScienceDirect containing the terms "HS-AD of SS" and "HS-AD". Notably, the numbers of such publications have increased in the last 15 years, with more than twice as many publications containing the term "HS-AD" than the term "HS-AD of SS" in this period. This indicates that HS$\mathrm{AD}$ has been mainly applied to the processing of non-SS organic wastes in the last 15 years, as confirmed by recent studies (Li et al., 2011; Fagbohungbe et al., 2015; André et al., 2018). In addition, a careful examination of the Fig. 1 shows that the annual number of published papers containing the term "HS-AD" did not increase from 2006 to 2010, but sharply increased after 2011. From 2006 to 2008 , fewer than 10 papers contained the term "HS-AD of SS", but this number rapidly increased from 2008 to 2017. It can be seen that all of the publications containing the term "HS-AD of SS" between 2006 and 2020 were research papers, and there has been no literature review of the research on HS-AD systems used to process SS. Accordingly, the aims of this paper are to provide a comprehensive review of the research progress in the development of HS-AD systems for SS processing, to identify knowledge gaps, and to discuss the future directions of research to improve the HS-AD of SS.

\section{Overview of current research on the HS-AD of SS}

\subsection{Factors affecting the HS-AD of SS}

Although the HS-AD of SS was proposed more than 20 years ago (PWRI, 1997; Hidaka et al., 2013), it is still not a widely used technique. The instability of HS-AD performance is a key bottleneck to its wide uptake. There are many factors that affect the stability of HS-AD of SS. According to the published literatures, the operating 


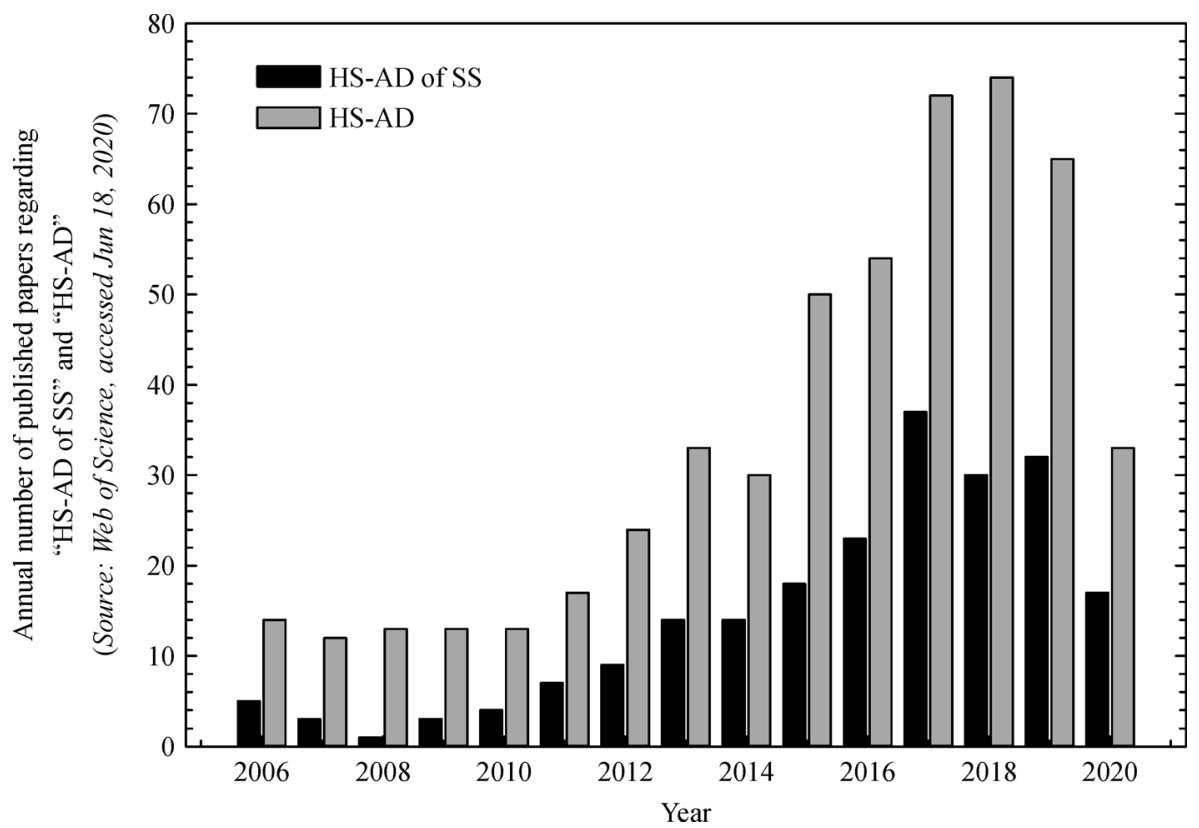

Fig. 1 ScienceDirect bibliometric study with the topics "high-solid anaerobic digestion (HS-AD) of sewage sludge (SS)" and "highsolid anaerobic digestion (HS-AD)" (June 2020).

factors and the intrinsic factors are two main factors affecting the HS-AD performance of SS. These main influencing factors are summarized in Table 1.

\subsubsection{The main operating factors affecting the HS-AD of SS}

Recently, Duan et al. (2012) proved that the semicontinuous mesophilic HS-AD of SS with HS concentrations of $10 \%, 15 \%$, and $20 \%$ was possible, which suggests that satisfactory stability of the HS-AD of SS can be achieved by adjusting the main process parameters. As shown in Table 1, the main operating parameters that affect the efficiency of HS-AD of SS - namely solid concentration, agitation, SRT, temperature, and $\mathrm{pH}-$ are thus regaining attention.

First of all, the most direct factor is the magnitude of the HS concentration, which has been considered to limit the efficiency and stability of HS-AD of SS (Lay et al., 1997; Liao et al., 2014). For example, Lay et al. (1997) investigated the effects of moisture content on the HSAD of SS under mesophilic conditions and found that the relative methanogenic activity decreased from $100 \%$ to $50 \%$ with a decrease in SS moisture content from $96 \%$ to $90 \%$, which indicated that the HS concentration restricted the mass and energy transport in the biochemical reactions of the HS-AD process. These findings were further confirmed by Le Hyaric et al. (2011), who have reported that a low water content in sludge decreased molecular diffusivity and resulted in a substantial decline in methanogenic activity. Liao et al. (2014) also found that with an increase of TS from $4.47 \%$ to $15.67 \%$, the slow degradation period was prolonged and the biogas yield decreased. They attributed these findings to the fact that a high TS concentration led to the rapid generation of a high concentration of metabolites (i.e., volatile fatty acids (VFAs) and ammonia), which then accumulated rather than being transformed further. Zhang et al. (2015 and 2016) demonstrated that the inhibition of mass transfer was a non-negligible problem during the HS-AD of SS, as they found that increasing TS from $6 \%$ to $15 \%$ without agitation led to sharp decreases in diffusion coefficients. They proposed that solid concentration has a significant influence on the mass transfer during HS-AD. Importantly, Liao and $\mathrm{Li}$ (2015) highlighted that the inhibition of mass transfer in HS sludge can be relieved by improved agitation. They conducted a pilot-scale HS-AD of SS for 9.5 months using an enhanced stirring system, and found that the VS reduction and biogas production were similar to those achieved by the LS-AD of SS, which was consistent with the findings of Duan et al (2012). These findings also suggest that the HS-AD of SS may need a special anaerobic digester with the enhancement of stirring impeller and mix system, which is different from the conventional anaerobic digester.

The SRT is a key parameter in the anaerobic treatment of SS. Typically, an appropriate SRT is crucial for balancing hydrolysis-acidification and methanogenesis in the HS-AD of SS. For example, it is well known that a long SRT leads to the increased removal of VS, especially from the slowly degradable organic matters of SS (Kapp H., 1984; Young et al., 2013; Jahn et al., 2016), while a long SRT decreases SS treatment efficiency and thus increases SS disposal costs (Young et al., 2013). Therefore, reducing SRT becomes an important way to improve the HS-AD of SS. 


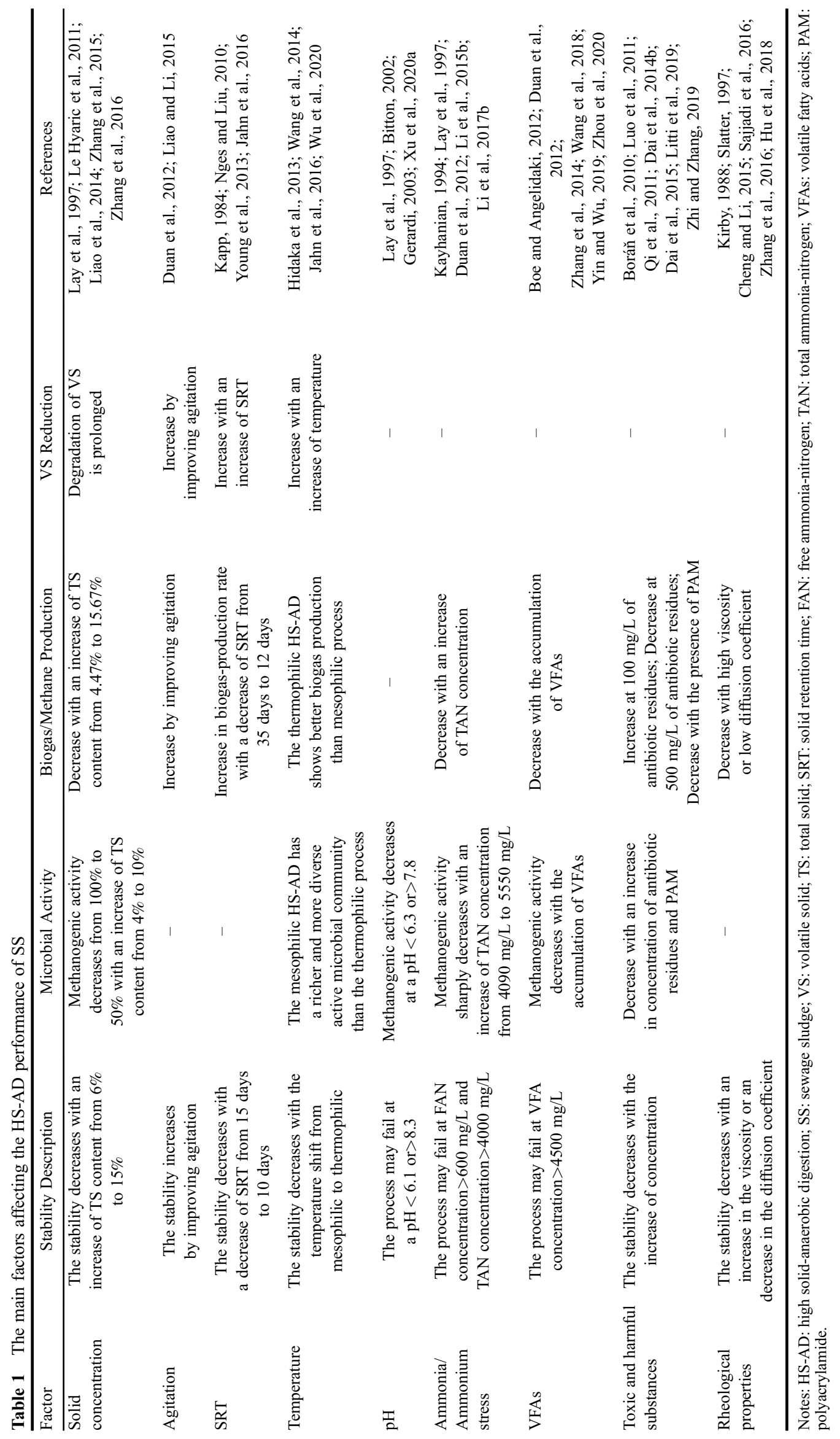


Nges and Liu (2010) shortened the SRT from 35 days to 12 days in the HS-AD of SS under both thermophilic and mesophilic conditions, and found that this increased the biogas-production rate and volumetric methane productivity, and decreased the VS-reduction efficiency. They also stated that the short SRT operation usually means more sludge can be treated and time is saved while utilizing the same facility (Nges and Liu, 2010). Jahn et al. (2016) studied the influence of SRT on the HS-AD of SS by performing $3.0 \mathrm{~L}$ semi-continuous experiments under mesophilic conditions. They found that the HS-AD of SS with an initial TS of $6.7 \%-7.8 \%$ was possible, as long as a minimal SRT of $15 \mathrm{~d}$ was ensured: the HS-AD of SS with a $10 \mathrm{~d}$ SRT resulted in an unstable process. These results were supported by the DWA (2014), who provided the design recommendations for digesters, including a minimum SRT of $15 \mathrm{~d}$. Moreover, STR usually correlates with the organic loading rate (OLR), and it is critical to the stable operation of HS-AD that the OLR is maintained in the range at which the rate of microbial decomposition of solids and metabolism of organic molecules is sufficient to prevent the accumulation of inhibitors (i.e., acids and free ammonia).

Temperature is another important operational parameter for the HS-AD of SS. Mesophilic and thermophilic temperature conditions are the most widely used for AD. Although thermophilic AD reduces VS more than mesophilic $\mathrm{AD}$, it is a more expensive process. In addition, microorganisms in thermophilic AD prefer a narrow temperature range, and thus temperature shifts can rapidly destabilise the process (Jahn et al., 2016). However, it is not clear which temperature is most favourable for the HSAD of SS. Hidaka et al. (2013) studied the performance of mesophilic and thermophilic HS-AD of SS in laboratoryscale continuous reactors for 600 days, and found that the performance of mesophilic HS-AD of SS with an initial TS content of $10 \%$ was stable at a total ammonia-nitrogen (TAN) concentration of $3000 \mathrm{mg} \mathrm{N} / \mathrm{L}$ and achieved a $60 \%$ VS removal, similar to the performance of LS-AD of SS. Conversely, the thermophilic HS-AD of SS with an initial TS content of $7.5 \%$ failed when the TAN concentration was $>2000 \mathrm{mg} \mathrm{N} / \mathrm{L}$, and a few weeks were required for the methanogenic activity to recover from inhibition. Hidaka et al. (2013) also revealed that the high viscosity of HS sludge created a challenge to its mesophilic processing, and that a more careful operation would be required for the stable thermophilic HS-AD of SS. In other work, Wu et al. (2020) also recently described a comparative study of mesophilic $\left(37^{\circ} \mathrm{C} \pm 2^{\circ} \mathrm{C}\right)$ and thermophilic $\left(53^{\circ} \mathrm{C} \pm 2^{\circ} \mathrm{C}\right)$ HS-AD of SS with an initial TS content of $10 \%$ at an OLR of $4 \mathrm{~g} \mathrm{VS} /(\mathrm{L} \cdot \mathrm{d})$ for 170 days, and found both the mesophilic and the thermophilic HS-AD of SS were stably maintained, although the thermophilic HS-AD was slightly inhibited by ammonia. They reported that the thermophilic HS-AD of SS showed better VS reduction and biogas production than the mesophilic process, but was more prone to inhibition by ammonia. They also found that the mesophilic HS-AD of SS was performed by a substantially richer and more diverse active microbial community than the thermophilic HS-AD of SS, which may explain why the thermophilic HS-AD of SS is a more unstable process. These findings were supported by Wang et al. (2014), who achieved the thermophilic HS-AD of SS with an initial TS content of $9.5 \%$, confirming the feasibility of this process.

As $\mathrm{pH}$ can influence enzymatic activity, it is another key parameter affecting the HS-AD of SS. It has been shown that the activity of methanogens decreases at a $\mathrm{pH}<6.3$ or $>7.8$ (Bitton, 2002; Xu et al., 2020a), and Gerardi (2003) determined that most anaerobic bacteria perform well at a $\mathrm{pH}$ range of 6.8-7.2. However, these findings were obtained under LS-AD conditions, so it is not clear whether this $\mathrm{pH}$ range is the most suitable for anaerobic bacteria in the HS-AD of SS. Based on calculations, Lay et al. (1997) proposed that a high rate of methane production during the HS-AD of SS was obtained at a $\mathrm{pH}$ of 6.8 , and that the process may fail at a $\mathrm{pH}<6.1$ or $>8.3$. In their study, the lag-phase time for methane production at $\mathrm{pH} 6.8$ reached a minimum in the HS-AD of SS with an initial TS content of 4\%-10\%. Unfortunately, the optimal $\mathrm{pH}$ value for the HS-AD of SS with an initial TS content $>10 \%$ has been rarely reported.

\subsubsection{The main intrinsic factors affecting the HS-AD of SS}

Although the HS-AD of SS is a promising technology that can be performed in smaller reactors and consumes less heating energy than LS-AD, the high concentration of potentially inhibitory substances (i.e., ammonia, VFAs, and toxic and harmful substances) released from HS SS and poor rheological properties of HS SS may deleteriously affect the efficiency of the AD process, as shown in Table 1.

It has been reported that the FAN concentration can reach up $600 \mathrm{mg} / \mathrm{L}$ in a stable system in which the HS-AD of SS was occurring (Duan et al., 2012), which is significantly higher than the inhibition threshold (200 $\mathrm{mg} / \mathrm{L}$ ) of conventional systems which perform the LS-AD of SS (Yenigün and Demirel, 2013; Liu et al., 2016b). It is notable that the HS-AD of SS is stable when the TAN is $4000 \mathrm{mg} / \mathrm{L}$, which is significantly greater than the inhibition threshold $(1000 \mathrm{mg} / \mathrm{L})$ for the HS-AD of other organic wastes (Kayhanian, 1994; Duan et al., 2012). This is presumably attributable to the special micro-ecosystems operating in the HS-AD of SS. It is clear that the overproduction of ammonium can inhibit methanogenesis, and this is a decisive factor that may significantly imbalance microbial community structure in an HS-AD process (Kayhanian, 1994; Li et al., 2015b; Li et al., 2017b). For example, Lay et al. (1997) found that methanogenic activity decreased by $10 \%$ with an increase in TAN concentration from $1670 \mathrm{mg} / \mathrm{L}$ to $3720 \mathrm{mg} / \mathrm{L}$, and decreased by $50 \%$ with an increase in TAN concentration 
from $4090 \mathrm{mg} / \mathrm{L}$ to $5550 \mathrm{mg} / \mathrm{L}$. Moreover, methanogenic activity was lost when the TAN concentration was $>5880$ $\mathrm{mg} / \mathrm{L}$. Li et al. (2017a) explored the effects of ammonium stress on metabolic pathways in bacterial and archaeal communities in the HS-AD of SS. As depicted in Fig. 2, three main methanogenic pathways including acetoclastic, hydrogenotrophic, and methylotrophic pathways were identified and the acetoclastic methanogenesis was the dominant pathway in the HS-AD of SS with the effects of ammonium stress. Li et al. (2017a) also revealed that in the HS-AD of SS, the expression of only 6 of the total 22 ammonium-related genes was upregulated, and that the expression of some amino-acid-related genes decreased under ammonium stress, thereby resulting in an acceleration of the syntrophic acetate oxidation reaction. For example, the acetate kinase (AckA) and phosphate acetyltransferase (PTA), which are involved in the reversible reaction of acetate conversion, enriched from 8670 and 6858 hits to 10004 and 7120 hits under ammonium stress, respectively, suggesting that the active syntrophic acetate oxidation performance with the effect of ammonium stress. Although how to effectively control ammonium stress in the HS-AD of SS is rarely reported, various strategies for recovering the $\mathrm{AD}$ performance of other organic wastes from ammonia inhibition have been studied (Rajagopal et al., 2013). For example, adding the biochars, zeolites, and activated carbon into the $\mathrm{AD}$ can reduce the ammonium level via adsorption reactions (Mumme et al., 2014; Cuetos et al., 2017; Poirier et al., 2017). In addition, Liu et al. (2020a) reported that the carbon- and iron-based additives (i.e., zero valent iron) can play important roles in accelerating microflora acclimation to tolerate ammonia stress. These strategies could provide some important references for relieving ammonia inhibition in the HS-AD process of SS.

The accumulation of VFAs is another problem with the HS-AD of SS. For example, Duan et al. (2012) reported that the VFAs concentration in a reactor in which the HS$\mathrm{AD}$ of SS was performed was as high as $4500 \mathrm{mg} / \mathrm{L}$, and that this led to the failure of the HS-AD process. Boe and Angelidaki (2012) also reported that at high OLR anaerobic digester is susceptible to failure due to the accumulation of VFAs, which is caused by an imbalance between syntrophic bacteria and methanogens. Typically, HS-AD has a high OLR and a low rate of diffusion of intermediate metabolites, with the former favouring the production of VFAs and the latter disfavouring the metabolism of VFAs. This therefore results in the accumulation of VFAs, which can directly cause the instability of the HS-AD of SS. Wang et al. (2018) found that the conventional process of interspecies hydrogen transfer (IHT) between anaerobic microorganisms was often inhibited in the HS-AD of SS, but that promoting the direct interspecies electron transfer (DIET) pathway in HS$\mathrm{AD}$ effectively prevented the accumulation of VFAs. Thus, they enhanced the DIET pathway in the HS-AD of SS by adding magnetite $\left(\mathrm{Fe}_{3} \mathrm{O}_{4}\right)$. It has been reported that adding scrap iron and nano zero-valent iron to a HS-AD system processing SS accelerates the conversion of VFAs into methane (Zhang et al., 2014; Zhou et al., 2020). For example, Zhang et al. (2014) reported that the scrap iron with ferric oxides on the surface can induce the microbial iron reduction, which accelerated the conversion of VFAs. Zhou et al. (2020) found that with the addition of nano zero-valent iron the propionic acid was more easily decomposed in HS-AD of SS. This result is consistent with the findings of Yin and $\mathrm{Wu}$ (2019), who revealed that the addition of conductive materials in $\mathrm{AD}$ system can effectively accelerate the degradation of propionate and butyrate via enhancing the DIET. In addition, Lv et al. (2020) proposed that enriching syntrophic associations to synchronously enhance their ecological function was a useful solution for alleviating VFAs accumulation. In related work, Nguyen et al. (2019) developed an intermittent oxidation-reduction potential (ORP)-controlled micro-aeration system to prevent the accumulation of VFAs in the HS-AD via regulating facultative heterotrophs. Specifically, they used micro-aeration to precisely control the ORP in AD and found that the VFAs were rapidly consumed by the facultative heterotrophs. They concluded that the intermittent ORP-controlled microaeration system could enrich the facultative heterotrophs and conserve crucial anaerobic niches for methanogens, and it was a useful tool for recovering the anaerobic digester on the verge of failure, which is due to the accumulation of VFAs. Although this finding is not based on the HS sludge system, it has an important reference for alleviating VFAs accumulation in the HS-AD process of SS.

Toxic and harmful substances in SS may also affect the efficiency of the HS-AD of SS, typically in a concentration-dependent manner. For example, Zhi and Zhang (2019) investigated the effects of antibiotic residues (i.e., residues of oxytetracycline, sulfadimethoxine, sulfamethoxazole, enrofloxacin, ciprofloxacin, ofloxacin, and norfloxacin) on the methane production and microbial activity during the HS-AD of SS. They found that low concentrations of antibiotics $(10 \mathrm{mg} / \mathrm{L})$ had no obvious effect on methane production; that medium concentrations $(100 \mathrm{mg} / \mathrm{L})$ significantly stimulated methane production; and that high concentrations $(500 \mathrm{mg} / \mathrm{L})$ inhibited methane production at the initial stage of the HS-AD process, but enhanced methane production after recovery at the late stage of the process. They also revealed that these antibiotics affected the archaeal community, but did not significantly affect the bacterial community. In related research, polyacrilamide (PAM), a refractory and common flocculant used in SS dewatering, has been found to be ubiquitous in HS sludge (Boráň et al., 2010; Qi et al., 2011; Dai et al., 2015; Litti et al., 2019). Dai et al. (2014b) determined that the biodegradation of PAM in SS processed via HS-AD was usually accompanied by the 
accumulation of high concentrations of toxic acrylamide monomers (AMs), which inhibited microbial activity (Luo et al., 2011). They also revealed that PAM can be hydrolysed at different position of its carbon-chain backbone, and that the hydrolysed PAM fragments combined with tyrosine-rich proteins to form colloid complexes during the HS-AD of SS. These findings were further confirmed by Litti et al. (2019), who reported that the addition of PAM led to decreased methane production in the HS-AD of SS. The researchers attributed this to the formation of large flocs and the consequent suppression of mass transfer. Unfortunately, the migration and transformation processes of these toxic and harmful substances during the HS-AD of SS remain unclear. However, these

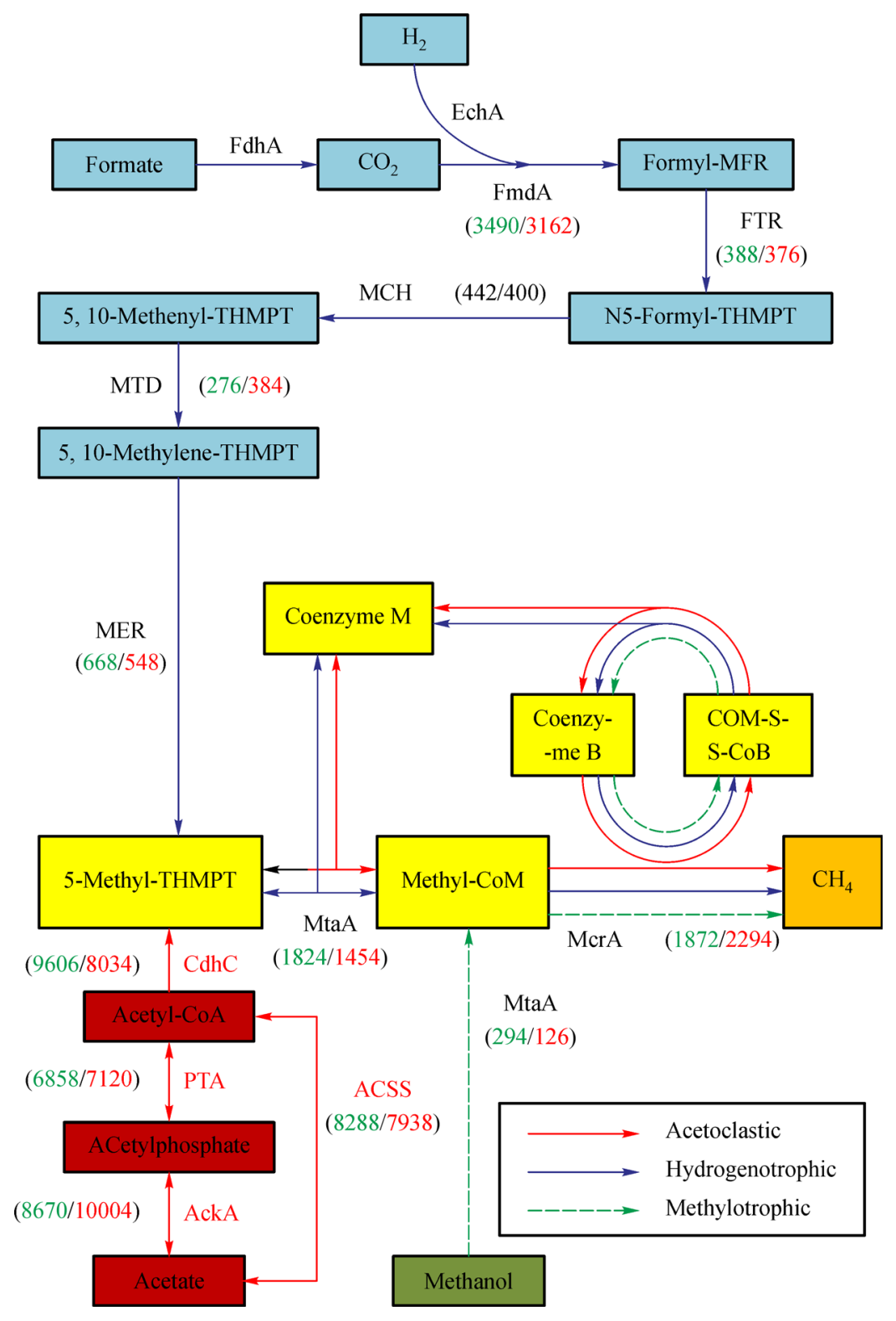

Fig. 2 Hit numbers of genes involved in the relevant methanogenesis pathways in HS-AD process of SS without and with ammonium stress (Reprinted from Li et al., 2017a, Copyright (2017), with permission from Elsevier).

(The acetoclastic pathway is shown in red, the hydrogenotrophic pathway is marked in blue, and the methylotrophic pathway is represented by the green dashed line).

Abbreviation: FdhA, glutathione-independent formaldehyde dehydrogenase; EchA, hydrogenase subunit A; FmdA, formylmethanofuran dehydrogenase subunit A; FTR, formylmethanofuran-tetrahydromethanopterin $\mathrm{N}$-formyltransferase; $\mathrm{MCH}$, methenyltetrahydromethanopterin cyclohydrolase; MTD, methylenetetrahydromethanopterin dehydrogenase; MER, coenzyme F420-dependent N5, N10-methenyltetrahydromethanopterin reductase; MtrA, tetrahydromethanopterin S-methyltransferase; MtaA, [methyl-Co(III) methanol-specific corrinoid protein]:coenzyme M methyltransferase; McrA, methyl-coenzyme M reductase alpha subunit; AckA, acetate kinase; ACSS, acetyl-CoA synthetase; PTA, phosphate acetyltransferase; HdrA, heterodisulfide reductase subunit A; CdhC, acetyl-CoA decarbonylase/synthase complex subunit beta. 
findings suggest that although high concentrations of metabolism-inhibiting substances may be present or formed during the HS-AD of SS, the tolerance of the system to these may be high, as long as its operating parameters are effectively controlled.

It has been reported that the rheological properties of SS play an important role in its performance in anaerobic digesters, especially in the design, selection, and operation of anaerobic digesters (Baudez et al., 2011; Baroutian et al., 2013; Dai et al., 2014a). Moreover, the rheological properties of normal SS with a TS content of $0.2 \%-4 \%$ have been well studied (Lotito et al., 1997; Ruiz-Hernando et al., 2013; Dai et al., 2014a). However, the rheological properties of HS sludge are different from those of the normal SS, and little relevant information is available on this topic (Kirby, 1988; Slatter, 1997; Cheng and Li, 2015). Therefore, it is necessary to reveal the characteristics of rheological properties of HS sludge. It is well known that an increase on SS concentration can result in an exponential increase in the viscosity of SS and an exponential decrease in its diffusion coefficient (Zhang et al., 2016). Cheng and Li (2015) found that HS sludge with a TS content of 7\%-15\% exhibited thixotropic properties. They also found that when the TS content increased to $6 \%, 8 \%, 10 \%$, and $12 \%$, the viscosities of the corresponding SSs increased by 5.0, 9.1, 25.7, and 24.9 times, respectively. Moreover, Zhang et al. (2016) reported that the diffusion coefficient of SS decreased sharply as the TS content increased from $6 \%$ to $12 \%$, and decreased gradually with an increase of TS content from $12 \%$ to $15 \%$. The high viscosity and low diffusion coefficient of HS SS can lead to non-uniform and non-ideal flow conditions (i. e., incomplete mixing, short circuiting, and an increase in inactive and stagnant zones) in anaerobic digesters (Sajjadi et al., 2016), which may further lead to the accumulation of VFAs and FAN, and thereby destabilise the HS-AD of SS. To improve the rheological properties of HS sludge, many studies have been conducted. For example, Feng et al. (2014) used thermal hydrolysis $\left(170^{\circ} \mathrm{C}, 60 \mathrm{~min}\right)$ treatment significantly decreased the viscosity, shear stress, and viscoelasticity of HS sludge, which is further confirmed by the findings of Urrea et al. (2015) and Zhang et al (2017). Liu et al. (2016c) investigated the effects of microwave$\mathrm{H}_{2} \mathrm{O}_{2}$ pretreatment on the rheological properties of $\mathrm{HS}$ sludge, and found that this method improved the sludge flowability and decreased the viscoelasticity. Furthermore, $\mathrm{Hu}$ et al. (2018) conducted a flow-field investigation and proposed that multilayer impellers arranged abreast could enable the more efficient mixing of HS sludge, given its rheological properties, and thus prevent the accumulation of VFAs and ammonia and any subsequent inhibition of HS-AD.

\subsection{Pre-treatment features of the HS-AD of SS}

The poor biodegradability and slow hydrolysis rate of SS limit the widespread adoption of AD processes. Inhibition of mass transfer, poor diffusion of intermediate metabolites, and high sludge viscosity are also a problem. Pretreating sludge has been reported to be effective in improving its biodegradability and hydrolysis via $\mathrm{AD}$ (Xu et al., 2020a). Many physical, chemical and biological pre-treatments (and combinations thereof) for LS sludge, prior to $\mathrm{AD}$, have been reported (Neumann et al., 2016; Gonzalez et al., 2018; Xu et al., 2020a), but only the thermal and alkaline methods have been used to pre-treat HS sludge prior to HS-AD (Jolis, 2008; Li et al., 2015a; Guo et al., 2016; Liao et al., 2016). Aside from economic reasons, these two pre-treatment methods may be favoured due to their substantial improvement of the rheological properties and organic solubilisation of HS SS, which enhances the HS-AD of SS. For example, Zhang et al. (2017) explored the effects of low- and high temperature thermal pre-treatments on HS SS (TS content of $14.2 \%$ and $18.2 \%$ ). They found that with increasing treatment time, organic solubilisation increased logarithmically and the elastic modulus in the linear viscoelastic regime of HS sludge decreased logarithmically, leading to a significant decrease in the SS viscosity, which was conducive to the subsequent HS-AD of the SS. The above results are also consistent with those reported by Xue et al. (2015) and Liao et al. (2016). The former showed that thermal pretreatment is an effective method of increasing the organic solubilisation and decreasing the viscosity of HS sludge. The latter investigated the effects of low temperature thermal pre-treatment on the HS-AD of SS, and found that this increased the quantity of accessible substrates, decreased sludge viscosity, and even resulted in an increase of biogas production in the HS-AD of SS. Alkaline pretreatment has also been used. Li et al. (2015a) proposed that HS sludge may be more amenable to such pretreatment than LS SS, as the same extent of SS disintegration could be achieved in HS SS as in LS SS, but with less alkali. After alkaline pre-treatment of $8 \%$ $12 \%$ TS SS (30 min treatment with $0.05 \mathrm{~mol} / \mathrm{L} \mathrm{NaOH})$, they found that methane production was slightly increased in the subsequent HS-AD process, while the digestion time was substantially decreased $(24 \%-29 \%)$. In addition, the positive effects of thermal and alkaline pre-treatment of SS have been combined in thermal-alkaline pre-treatment. For example, Guo et al. (2016) explored the effects of thermalalkaline pre-treatment $\left(105^{\circ} \mathrm{C}-135^{\circ} \mathrm{C}\right.$ and $5-35 \mathrm{mg} \mathrm{NaOH} /$ g TS) on the HS-AD of SS, and concluded that this pretreatment significantly increased organic solubilisation and methane production during HS-AD. However, although the thermal-alkaline pre-treatment is conductive to the hydrolysis of sludge organic matter and more bio-methane can be further transformed by the organic solubilisation and hydrolysis, some organic pollutants and toxic substances will also be released during this pre-treatment process. The concentrations of organic pollutants and toxic substances released from the HS sludge could be far higher 
than those released from the LS sludge, and these pollutants and toxic substances also could affect the subsequent HS-AD. Unfortunately, current researches on the thermal-alkaline pretreatment of HS sludge prior the HS-AD of SS have ignored this point.

\subsection{HS anaerobic co-digestion of SS and other organic} wastes

Exploiting the characteristics of different organic wastes for energy recovery and waste disposal can optimise resource utilisation. As such, HS anaerobic co-digestion (HS-AcD) of SS and other organic waste is a promising method of the utilisation and management of organic waste. Notably, HS-AcD may be a more stable method than HS-AD of processing SS, due to its dilution of inhibitory substances, improvement of nutrient balance, and creation of synergies between microorganisms (Dai et al., 2013; Aichinger et al., 2015; Lee et al., 2019). Lee et al. (2019) successfully conducted a long-term HS-AcD of $\mathrm{SS}$, food waste (FW) and yard waste (YW), achieving an average VS reduction of $38 \%$ and methane production of $186 \mathrm{~mL} / \mathrm{g}$ VS. They investigated the effects of the ratio of substrate to inoculum $(\mathrm{S} / \mathrm{I})$, the mixing ratio of cosubstrate, the inoculum source, and the alkalinity sources on HS-AcD performance, and found that the highest methane production was obtained using the mixture of $\mathrm{NaHCO}_{3}$ and oyster shells as alkaline sources with the S/I ratio of 1 (VS basis). Moreover, the presence of FW led to a 1.43-fold higher methane production than from the HSAD of SS. They also proposed that the mixing ratio of cosubstrate, the S/I, and the inoculum source are important operational factors for the successful long-term performance of HS-AcD. Similarly, Dai et al. (2013) compared the stability and performance of the HS-AcD of SS and FW with those of the HS-AD of SS, and found that the addition of FW improved both system stability and volumetric biogas production. This was primarily attributed to the dilution of ammonia and sodium ions. The researchers also revealed that the mixing ratio of SS and FW determined the performance of their HS-AcD system. This finding was confirmed by two further studies by Liu et al. (2016a) and Latha et al. (2019). Liu et al. (2016a) found that the processing of LS sludge (VS/TS 41.6\%) via HS-AcD was optimal with a 1:1 SS:FW mixing ratio (VS basis) in a weak alkaline environment ( $\mathrm{pH} 7.5-8.5)$, as this led to the best synergetic effect. Latha et al. (2019) determined that the optimum mixing ratio of SS and FW in their HS-AcD process was 1:3 (TS basis), with intermittent biogas recirculation, and that this mixing strategy increased the synergy of $\mathrm{CO}_{2}$ acidification with high VFAs production. Cattle manure $(\mathrm{CM})$ is another organic waste that is often used for $\mathrm{AcD}$ with $\mathrm{SS}$, because $\mathrm{CM}$ is unstable to $\mathrm{AD}$, due to the low $\mathrm{C} / \mathrm{N}$ ratio of $\mathrm{CM}$ ( $\mathrm{Li}$ et al., 2009). Dai et al. (2016) investigated the HS-AcD of SS and CM and found that the optimum mixing ratio (VS basis) of SS and CW was 3:7 with an initial $\mathrm{pH}$ of 9.0, yielding a maximum VFAs production of $98.33 \mathrm{~g} / \mathrm{kg}$ TS and methane production of $>120.0 \mathrm{~L} / \mathrm{kg}$ TS. They also highlighted that CM increased the relative abundances of bacteria and archaea and the degradation of organic matters under the optimum conditions.

2.4 Characteristics of substance transformation in the HS$\mathrm{AD}$ process of $\mathrm{SS}$

\subsubsection{Organic humification in the HS-AD of SS}

Organic humification has been widely considered an important index of stabilisation in the treatment of SS (Bernal et al., 2009), and can be realised in the AD of SS (Provenzano et al., 2016; Xu et al., 2020b). Therefore, the humification of SS organic matter must be explored to improve stabilisation during the HS-AD of SS. To reveal the underlying mechanisms of humic formation and transfiguration in the HS-AD of SS, Tang et al. (2018) monitored the aromaticity degree of humic-like substances and the phytotoxicity of the digestate during a 48-day HSAD of SS. They found that there were significant repolymerisation of aromatic substances and a positive correlation between digestate phytotoxicity and the degree of substance aromaticity. They also proposed that the aromatic repolymerisation of humics regulated the phytotoxicity of digestate via reducing excessive salinity. Based on these findings, they further investigated the effect of humification on extracellular polymeric substances (EPS) in the HS-AD of SS (Tang et al., 2020), and found that the hydrolysis and decomposition of extracellular protein generated changes in the highly cross-linked structures of humics in EPS, resulting in the exposure of humic aromatic groups and binding sites. Based on analysis of the electron exchange capacity and the metabolic activity of methanogenesis, they proposed that structural changes in EPS proteins promoted the catabolism and anabolism of anaerobic microorganisms, and that the products of this metabolism, such as humic groups and active protein derivatives, were beneficial to EPS reconstruction in the HS-AD of SS.

2.4.2 Characteristics of organic transformation in the HS$\mathrm{AD}$ of SS with and without thermal pre-treatment

As is well known to all, with the increase of TS content, the physical, chemical and even biological reactions in the HS$\mathrm{AD}$ process of SS could be changed because of the blocked mass transfer, poor diffusion, and high viscosity. As a result, the transformation of sludge organic matter would inevitably be affected in the HS-AD process, and understanding this transformation process is necessary to improve the HS-AD of SS. Han et al. (2017) investigated 
the organic transformation process during the HS-AD of SS with and without thermal pre-treatment, by monitoring variations in the chemical oxygen demand, and in the production of methane, carbohydrates, VFAs, and other substances in SS containing nitrogen, sulphur and phosphorus, as described in Fig. 3. They found, for example, that thermal pre-treatment significantly enhanced the biogas production rate during the HS-AD of SS, and resulted in increased methane content in the biogas. Without thermal pre-treatment, the biogas production rate and methane content yielded by the HS-AD of SS were similar to those yielded by conventional AD. The above findings were further supported by Chen et al. (2018), who found that thermal pre-treatment shifted the methanogenic pathway from strict acetoclastic methanogenesis to acetoclastic/hydrogenotrophic methanogenesis. In addition, Han et al. (2017) found that thermal pre-treatment led to more than $50 \%$ of the particulate nitrogen being converted to a liquid-state during HS-AD, and that the TAN concentration was increased to $3.57 \mathrm{~g} / \mathrm{L}$. However, there was little effect on the transformation of phosphorus: regardless of pre-treatment, $32 \%-35 \%$ of total phosphorous (organic phosphorous and polyphosphate) was converted to phosphate, primarily by the hydrolysis of polyphosphate. One possible reason given by Liu et al. (2020b) is that the thermal pre-treatment can improve the release of phosphate, but this phosphate was subsequently converted into a solid state during the HS-AD process by precipitation as struvite $\left(\mathrm{NH}_{4} \mathrm{MgPO}_{4} \cdot 6 \mathrm{H}_{2} \mathrm{O}\right)$, precipitation with high concentrations of heavy metals, and adsorption into microbial cells via the synthesis of adenosine triphosphate (ATP). They also proposed that the neutralization of the release of phosphate and redeposition makes it reasonable that the HS-AD process of SS with thermal pre-treatment has little effect on the transformation of phosphorus.

It has been reported that the $\mathrm{H}_{2} \mathrm{~S}$ content of biogas generated by the HS-AD of SS with or without thermal pre-treatment is far lower than the $\mathrm{H}_{2} \mathrm{~S}$ content of biogas generated by the LS-AD of SS. For example, Han et al. (2017) found that in their HS-AD of SS that the maximum $\mathrm{H}_{2} \mathrm{~S}$ content in biogas was $168.0 \pm 19.2 \mathrm{mg} / \mathrm{L}$, which was far lower than that from the LS-AD of SS (approximately $1500 \mathrm{mg} / \mathrm{L}$ ). This result was also confirmed by Liao (2016), who found that the $\mathrm{H}_{2} \mathrm{~S}$ content of biogas generated by $\mathrm{AD}$ decreased with an increase in TS content, and that a maximum $\mathrm{H}_{2} \mathrm{~S}$ content of approximately $45 \mathrm{mg} /$ $\mathrm{L}$ was present in biogas generated by the HS-AD of SS with a TS of $20 \%$. This phenomenon was attributable to the effects of $\mathrm{pH}$, heavy metals, and the hydrolysis of sulphurous proteins, as follows. 1) $\mathrm{As}_{2} \mathrm{~S}$ is an acidic gas, it is consumed at a high $\mathrm{pH}$; notably, the $\mathrm{pH}$ was 8.0 during the HS-AD of SS, which was greater than that during the LS-AD of SS (pH 7.0-7.5). 2) An increase in TS content results in the concentration of heavy metals in the
HS-AD of SS being greater than that in the LS-AD, leading to the increased precipitation of heavy metal sulfides. 3) Due to the inefficient hydrolysis of sulphurous proteins during the HS-AD of SS, concentrations of sulphurcontaining compounds remain low (Dai, 2016; Liao, 2016; Han et al., 2017). Another interesting phenomenon involving sulphurous substances was reported by $\mathrm{Li}$ et al. (2020), who found that the thermal pre-treatment of SS made HS-AD able to directly promote the transformation of organic sulphur (OS) into volatile sulphur compounds (VSCs). They found that methyl mercaptan (MM), dimethyl sulfide (DMS), dimethyl disulfide (DMDS), and $\mathrm{H}_{2} \mathrm{~S}$ were typical VSCs, and that MM was converted into DMS (18\%), DMDS (4\%), and $\mathrm{H}_{2} \mathrm{~S}(78 \%)$ in biogas generated from the HS-AD of SS with an initial TS content of $10 \%$, when SS had been thermally pre-treated. They also revealed that thermal pre-treatment increased the activity of reductases such as adenine phosphate sulfate reductase and sulfite reductase. These findings supported those of previous researchers (Sommers et al., 1977; Higgins et al., 2006; Moestedt et al., 2013; Dai et al., 2017), and the conversion pathway of sulphur substances during the HS-AD of SS with thermal pre-treatment is depicted in Fig. 4. For example, the initial OS content of sludge decreased from $96 \%$ to $90 \%$ with thermal pretreatment, specifically, the initial methionine and cysteine contents of sludge decreased from $61 \%$ and $35 \%$ to $59 \%$ and $31 \%$, respectively. However, the conversion pathway of sulphur substances during the HS-AD of SS without pre-treatment has rarely been reported, although knowledge of this is important for establishing a theoretical system for the HS-AD of SS, to enable improvement of HS-AD processes.

\section{Knowledge gaps of current research on the HS-AD of SS}

\subsection{The definition of HS sludge is not standardised}

As yet, there is no standard definition of HS sludge. For example, some researchers have reported conducting HS$\mathrm{AD}$ of an SS, and yet the TS content of the SS they used was only 4\% (Lay et al., 1997). Chen et al. (2019) studied the HS-AD of SS with an initial TS of $5 \%$, while others have used SSs with an initial TS of 10\%, 15\%, and 20\%, respectively (Duan et al., 2012), These different definitions of HS sludge mean that it is difficult to evaluate the feasibility and applicability of the HS-AD of SS with different TS contents, especially as the properties of SS from different WWTPs are also different. Even more importantly, without a standard definition of HS sludge, many research results can neither be effectively compared nor function as references for establishing a theoretical system of the HS-AD of SS. 

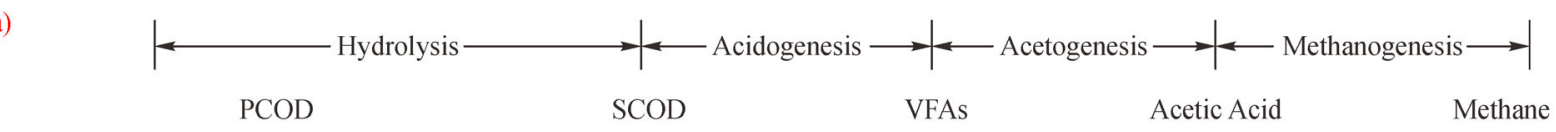

MAD

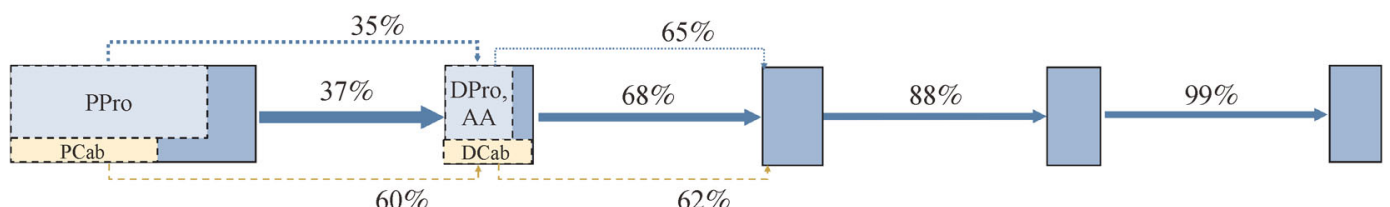

$\underline{\text { TAD }}$
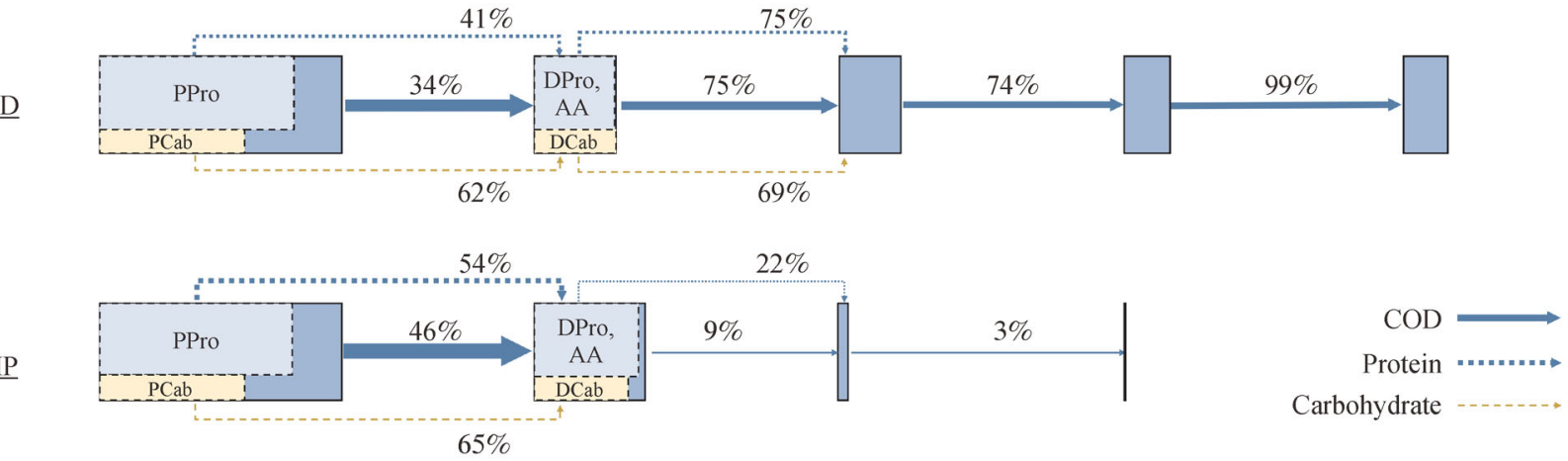

COD

THP

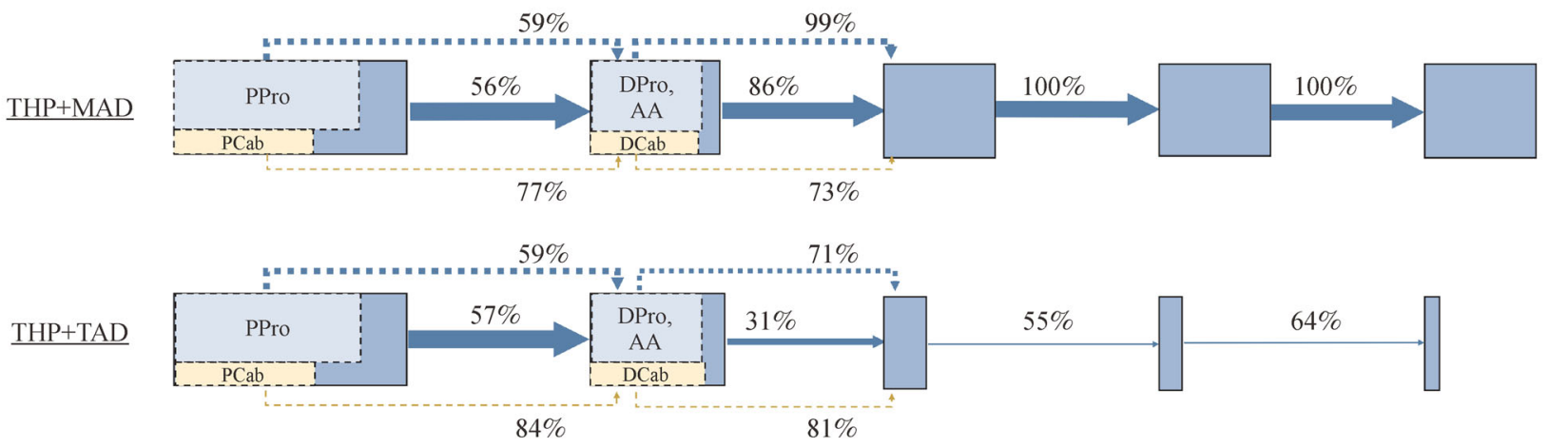

(b)

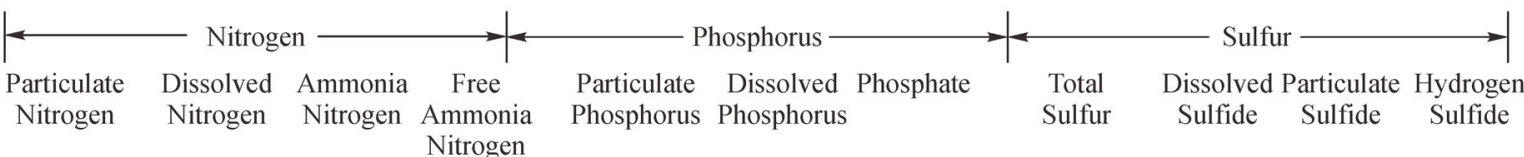

MAD
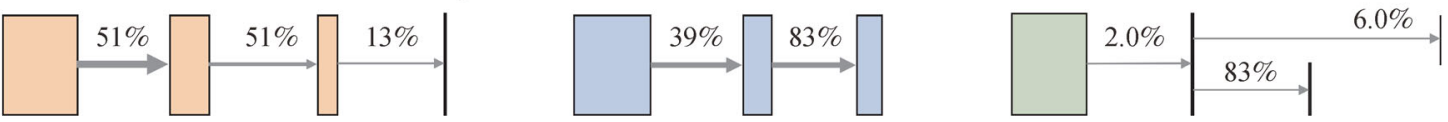

TAD
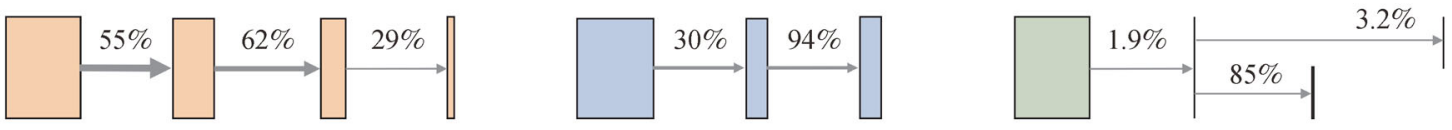

THP
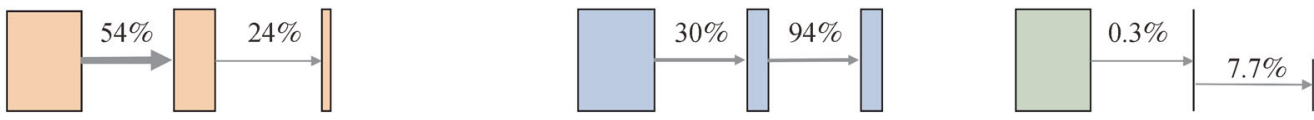

THP+MAD
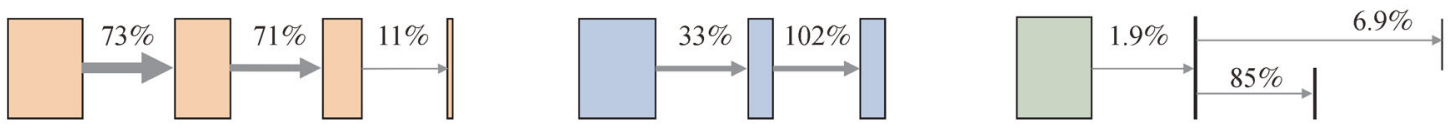

THP+TAD
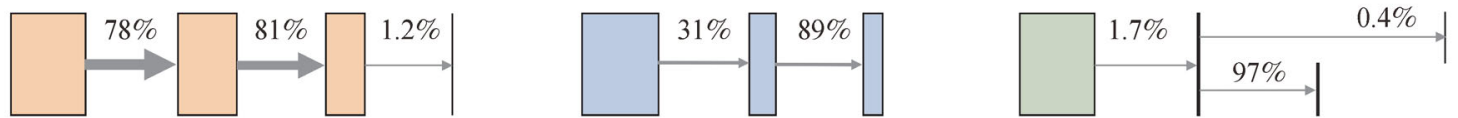

Fig. 3 The diagram of the substance transformation ratios in the mesophilic/thermophilic HS-AD process of SS with and without thermal pre-treatment: (a) the diagram of the transformation ratios of COD, protein and carbohydrate; (b) the diagram of the transformation ratios of nitrogen, phosphorus and sulphur (Reprinted from Han et al., 2017, Copyright (2017), with permission from Elsevier). 


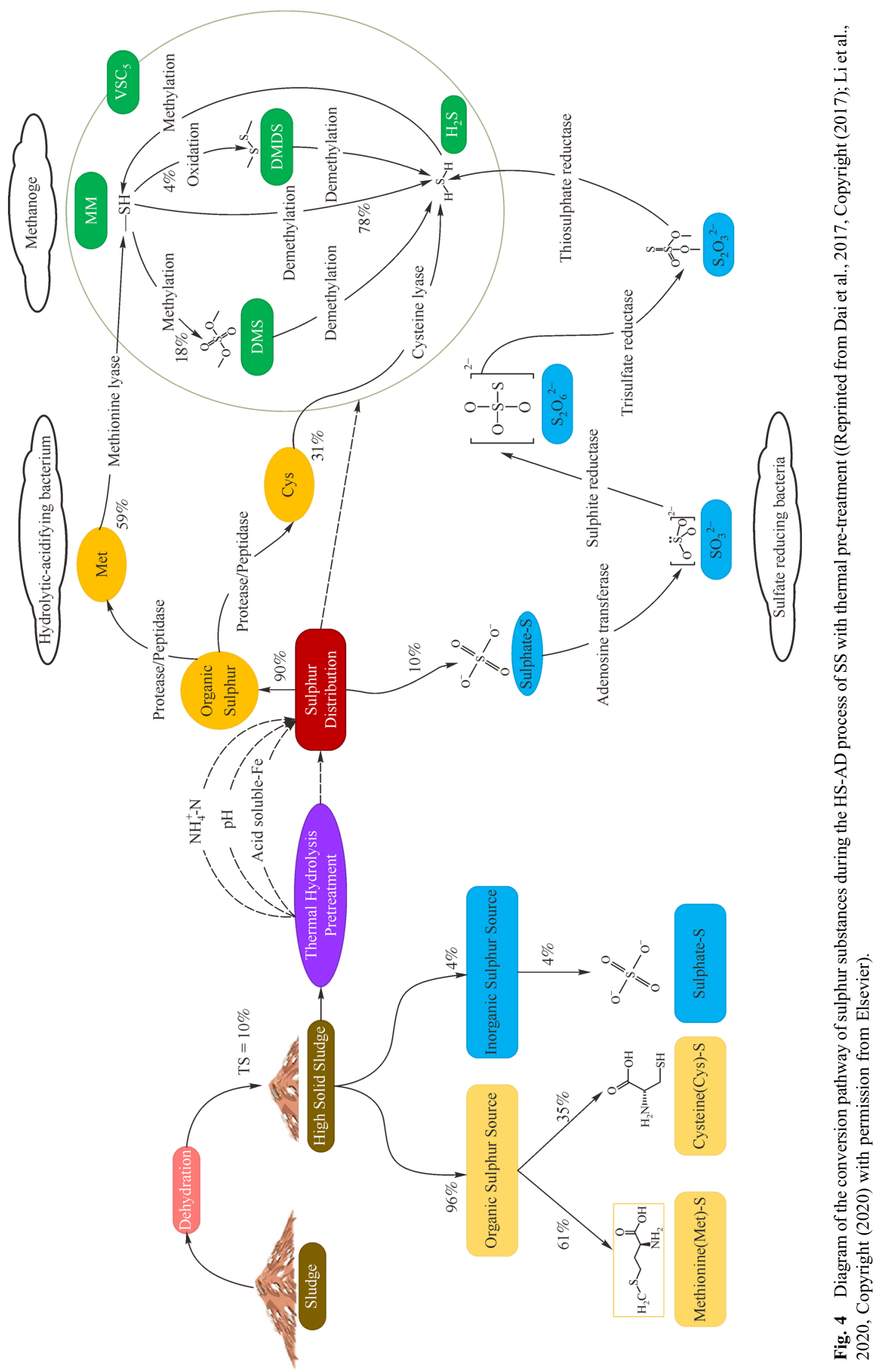


3.2 Migration and transformation of pollutants in the HS$\mathrm{AD}$ of $\mathrm{SS}$ is unclear

It has been reported that SS contains the inert organic pollutants (e.g., microplastics, benzene, chlorophenol, polychlorinated biphenyls, polychlorinated dibenzofurans etc.), inorganic pollutants (e.g., heavy metals), and microbial pollutants (e.g., enterovirus, bacillus coli, protozoan, parasites, and their eggs) (Li et al., 2018; Száková et al., 2019; Souza et al., 2020). Although the concentrations of these pollutants are low in the normal SS with a TS content of $0.2 \%-2 \%$, these concentrations may increase with the increase of TS content and the pollutants are environmentally persistent and potentially toxic. More seriously, based on the limited detection method, it is difficult to determine the migration and transformation of organic pollutants in sludge, which also restricts the understanding and development of HS-AD process of SS to a certain extent. Therefore, enough attention should be paid to the migration and transformation of these pollutants in the subsequent treatment. However, it is unclear that the migration and transformation of these pollutants in the HS$\mathrm{AD}$ process of SS up till the present moment.

\subsection{Metabolic pathways of organic matter in the HS-AD of} SS are not known

Although the metabolic pathways of organic matter in $\mathrm{AD}$ are well known (Pavlostathis and Giraldo-Gomez, 1991; Batstone et al., 2002), they have been determined mainly based on the AD of complex composite particulate waste (CCPW), which can be assumed to be homogeneous (Batstone et al., 2002). This approach is suitable for describing the fate of CCPW in systems such as wastewater or waste-activated sludge (TS $0.2 \%-2 \%$ ), because the inherent properties of CCPW can be effectively maintained by retaining sufficient water in these systems. However, with increasing solid concentrations, the water content of the CCPW decreases and the adjacent microenvironment of the CCPW changes, which profoundly alters the adjacent ionic strength. This leads to changes in the micro-interfaces between the CCPW and water, and subsequent changes in the interfacial structure and properties of the CCPW, ultimately causing a substantial difference in the metabolic pathways operating during the HS-AD of CCPW vs those operating during the LS-AD of CCPW. Therefore, the specific metabolic pathways of CCPW during HS-AD of SS must be investigated to enrich the theory of $\mathrm{AD}$ and provide a direct theoretical basis for improving the HS-AD of SS. However, information on this has rarely been reported.

3.4 The mathematical model for the HS-AD of SS is inadequate

Process stability and performance are two key bottlenecks to the application of large-scale HS-AD of SS (Duan et al., 2012; Liao et al., 2014), and it is very important to evaluate and predict the process stability and performance of HSAD of SS. Mathematical modelling has been widely regarded as an important tool to assess and predict process performance (Mendes et al., 2015). The anaerobic digestion model No. 1 (ADM1) has been used to evaluate and predict the HS-AD of SS for more than 15 years, but it is better suited to predicting the $\mathrm{AD}$ of wastewater or LS sludge (TS $0.2 \%-2 \%$ ) than that of HS sludge (AbbassiGuendouz et al., 2012; Mendes et al., 2015). In recent years, with the development of solid-state AD process, the mathematical model of solid-state AD of organic waste have been widely proposed and studied (Xu et al., 2015; Wang et al., 2016), however, due to the large differences in the structure and properties of SS compared with other organic wastes, it is difficult to apply the mathematical model of solid-state AD of organic waste to describe the HS-AD of SS. Consequently, the use of HS-AD of SS is hindered by the inability to accurately predict its stability and performance. Therefore, to improve the HS-AD of SS, a relevant mathematical model is urgently needed.

\section{Future perspectives on HS-AD process of SS}

Although HS-AD has been successfully applied to treat organic waste, there have been comparatively few studies of its utility in treating SS. Indeed, the above overview shows that research on HS-AD of SS is in its infancy, and many questions remain open.

As mentioned, there is no standard definition of HS SS, and the optimal TS content of SS for AD treatment is undetermined. The development of sludge dewatering means that high TS contents of SS can be easily obtained. Thus, a definition of HS sludge and the optimal TS content of SS for AD should be explored. An increase in TS content will, however, inevitably alter the structure and properties of SS; thus, it would be reasonable to define HS sludge according to its structure and properties. For example, there is no significant difference in sludge structure within a certain range of TS content. Therefore, a TS content that causes significant changes in sludge structure should be used as a basis for a standard definition of HS sludge. Similarly, a TS content that causes significant changes in certain key properties of sludge, such as its diffusion coefficient or viscosity, should also be considered in making such a definition. Moreover, in order to reduce digester volume and improve sludge treatment efficiency, the HS-AD is proposed via increasing the TS content of sludge. This means that it should be possible to substantially increase the TS content of SS without affecting the AD treatment efficiency of SS. However, due to the unique semi-rigid structure of sludge and the variety of potential inhibitors within sludge that may 
inhibit anaerobic microorganisms, a high TS content will lead to the formation of multi-material cross-linking structures that are resistant to biodegradation and an increase in inhibitor concentration. It therefore likely that there is an optimal TS content for the HS-AD of SS, and this should be determined by exploring the effect of various TS contents on HS-AD of SS.

The migration and transformation of substances underpin the HS-AD of SS, and must be understood at a mechanistic level to enable the overall process to be enhanced. There have been some studies on the migration and transformation of substances in SS, but these have focused on the transformation of readily biodegradable organic matter (e.g., proteins, carbohydrates, and VFAs) and nutrients (i.e., nitrogen, sulphur, and phosphorus) in the solid, liquid, and gas phases. The related transformation mechanisms and metabolic pathways of these substances in the HS-AD of SS are rarely reported. For example, the differences between the quantitative transformation of proteins, carbohydrates, and lipids are unknown, as are the differences between the metabolic pathways of proteins, carbohydrates, and lipids in the HSAD of SS. More deeply, the underlying mechanisms of electron transfer (i.e., DIET) between bacteria and archaea via the transformation of these substances in HS-AD of SS are still blank and need to be further revealed in future. Moreover, knowledge of the migration and transformation of toxic and harmful pollutants (i.e., inert organic pollutants, inorganic pollutants, and microbial pollutants) in sludge will aid in their elimination and in the stabilisation of SS treatment. Two key questions warrant attention, as follows: 1) Which toxic and harmful pollutants in sludge are degraded and what are the pathway and extent of this degradation in the HS-AD of SS? 2) What are the distributions of these toxic and harmful pollutants in the solid, liquid and gas phases during the HS$\mathrm{AD}$ of SS? Future research must establish the fundamental metabolic transformations of organic matter in SS and the migration and transformation characteristics of toxic and harmful pollutants in the HS-AD of SS, to afford a strong knowledge platform for further understanding the HS effect and improving the HS-AD of SS.

To overcome the key bottlenecks to the application of HS-AD of SS, a relevant mathematical model that can accurately predict the stability and performance of this process should be established as soon as possible. To date, the HS-AD of SS has usually been operated empirically, as there is no mathematical tool available for improving parameter control, explicating mechanisms, and predicting process performance. It is time-consuming to determine and optimise experimental parameters for the HS-AD of $\mathrm{SS}$, and the resulting parameters and their values are not universally applicable. This underscores the need for accurate mathematical models. Whilst mathematical models for the HS-AD of other organic wastes are well established ( $\mathrm{Xu}$ et al., 2015), these are not suitable for application to modelling the HS-AD of SS, due to the substantial difference in the structure and properties of other organic wastes compared with those of SS. However, it is logical and it should be feasible to develop mathematical models for the HS-AD of SS that are based on the ADM1 and the reported mathematical tools for the HS-AD of organic wastes. For example, retarded hydrolysis of the substrate and poor microbial access to the substrate are two key problems in the processing of both SS and other organic wastes. Hence, developing an understanding of the interfacial properties of and the mass transfer that occurs in the solid, liquid, and gas phases in the HS-AD of other organic wastes will inform the development of mathematical models for the HS-AD of SS.

In addition, the effects of sludge dewatering agents on the HS-AD of SS should be further explored, because most HS sludges contain a certain amount of dewatering agents. The underlying relationships between the dewatering agent and the HS-AD of SS should be established and the development of readily biodegradable dehydrators that do not degrade to molecules that may inhibit anaerobic microorganisms should be considered. With the HS effects, the concentrations of high value-added products (HVAP, e. g., lactic acid, biological protein, polyhydroxyalkanoates, and poly- $\beta$-hydroxybutyrate) within sludge increased with the increase of TS content, which suggests that attentions should also be paid to the studies of obtaining the HVAP from HS-AD process of SS and the effects of HVAP on HS-AD of SS in future.

\section{Conclusions}

The HS-AD of SS has been proposed as an attractive option for SS treatment, as it requires only small reactors and has a high volumetric biogas productivity and low heating-energy demand. This paper comprehensively reviews the current research on the main factors affecting process stability and performance, the improvement methods including pre-treatment and HS-AcD of SS and other organic wastes, and the characteristics of substance transformation. The results of current studies indicate that the poor stability and performance of the HS-AD of SS are the main bottlenecks to its wide application. These bottlenecks are due to the HS effect, manifested in the HS-AD of SS by high concentrations of substances that may inhibit anaerobic microorganisms, and in poor mass transfer, low diffusion coefficients, and high viscosity. The main knowledge gaps are the absence of a standard definition of HS sludge, insufficient knowledge of the migration and transformation of pollutants, particularly the specific metabolic pathways involved, and a lack of mathematical models. Attention should be paid to addressing these knowledge gaps in future work in this important area. In addition, future efforts on developing the green 
sludge dewatering agents, obtaining the high value-added products, and revealing their effects on HS-AD process of SS can also be considered.

Conflict of interest The authors declare no competing financial interest.

Acknowledgements This work was financially supported by the National Natural Science Foundation of China (NSFC) (Grant Nos. 51978498 and 51538008), the Support Program of Postdoctoral Innovative Talents (BX20190239), the China Postdoctoral Science Foundation (2020M671227), and the National Key R\&D Program of China (2019YFC1906301).

Open Access This article is licensed under a Creative Commons Attribution 4.0 International License, which permits use, sharing, adaptation, distribution and reproduction in any medium or format, as long as you give appropriate credit to the original author(s) and the source, provide a link to the Creative Commons licence, and indicate if changes were made. The images or other third party material in this article are included in the article's Creative Commons licence, unless indicated otherwise in a credit line to the material. If material is not included in the article's Creative Commons licence and your intended use is not permitted by statutory regulation or exceeds the permitted use, you will need to obtain permission directly from the copyright holder. To view a copy of this licence, visit http://creativecommons.org/licenses/by/4.0/.

\section{References}

Abbassi-Guendouz A, Brockmann D, Trably E, Dumas C, Delgenès J P, Steyer J P, Escudié R (2012). Total solids content drives high solid anaerobic digestion via mass transfer limitation. Bioresource Technology, 111: 55-61

Aichinger P, Wadhawan T, Kuprian M, Higgins M, Ebner C, Fimml C, Murthy S, Wett B (2015). Synergistic co-digestion of solid-organicwaste and municipal-sewage-sludge: 1 plus 1 equals more than 2 in terms of biogas production and solids reduction. Water Research, 87: 416-423

André L, Pauss A, Ribeiro T (2018). Solid anaerobic digestion: State-ofart, scientific and technological hurdles. Bioresource Technology, 247: 1027-1037

Baroutian S, Eshtiaghi N, Gapes D J (2013). Rheology of a primary and secondary sewage sludge mixture: dependency on temperature and solid concentration. Bioresource Technology, 140: 227-233

Batstone D J, Keller J, Angelidaki I, Kalyuzhnyi S V, Pavlostathis S G, Rozzi A, Sanders W T M, Siegrist H, Vavilin V A (2002). Anaerobic Digestion Model No.1. Scientific and Technical Report 13. London, UK: IWA Publishing

Baudez J C, Markis F, Eshtiaghi N, Slatter P (2011). The rheological behaviour of anaerobic digested sludge. Water Research, 45(17): 5675-5680

Bernal M P, Alburquerque J A, Moral R (2009). Composting of animal manures and chemical criteria for compost maturity assessment. A review. Bioresource Technology, 100(22): 5444-5453

Bitton G (2002). Encyclopedia of Environmental Microbiology. New York: John Wiley \& Sons, Inc.

Boe K, Angelidaki I (2012). Pilot-scale application of an online VFA sensor for monitoring and control of a manure digester. Water Science and Technology, 66(11): 2496-2503

Borán̆ J, Houdková L, Elsäßer T. (2010). Processing of sewage sludge: dependence of sludge dewatering efficiency on amount of flocculant. Resources, Conservation and Recycling, 54(5): 278-282

Chen R, Wen W, Jiang H, Lei Z, Li M, Li Y Y (2019). Energy recovery potential of thermophilic high-solids co-digestion of coffee processing wastewater and waste activated sludge by anaerobic membrane bioreactor. Bioresource Technology, 274: 127-133

Chen S, Li N, Dong B, Zhao W, Dai L, Dai X (2018). New insights into the enhanced performance of high solid anaerobic digestion with dewatered sludge by thermal hydrolysis: Organic matter degradation and methanogenic pathways. Journal of Hazardous Materials, 342: $1-9$

Cheng Y, Li H (2015). Rheological behavior of sewage sludge with high solid content. Water Science and Technology, 71(11): 1686-1693

Cuetos M J, Martinez E J, Moreno R, Gonzalez R, Otero M, Gomez X (2017). Enhancing anaerobic digestion of poultry blood using activated carbon. Journal of Advanced Research, 8(3): 297-307

Dai L (2016). The characteristics and the sulphur control technology of the high solid anaerobic digestion in WWTP. Dissertation for the Master Degree. Xi'an: Xi'an University of Architecture and Technology

Dai X, Chen Y, Zhang D, Yi J (2016). High-solid anaerobic co-digestion of sewage sludge and cattle manure: The effects of volatile solid ratio and $\mathrm{pH}$. Scientific Reports, 6(1): 35194

Dai X, Duan N, Dong B, Dai L (2013). High-solids anaerobic codigestion of sewage sludge and food waste in comparison with mono digestions: stability and performance. Waste Management (New York, N.Y.), 33(2): 308-316

Dai X, Gai X, Dong B (2014a). Rheology evolution of sludge through high-solid anaerobic digestion. Bioresource Technology, 174: 6-10

Dai X, Hu C, Zhang D, Dai L, Duan N (2017). Impact of a high ammonia-ammonium-pH system on methane-producing archaea and sulfate-reducing bacteria in mesophilic anaerobic digestion. Bioresource Technology, 245(Pt A): 598-605

Dai X, Luo F, Yi J, He Q, Dong B (2014b). Biodegradation of polyacrylamide by anaerobic digestion under mesophilic condition and its performance in actual dewatered sludge system. Bioresource Technology, 153: 55-61

Dai X, Luo F, Zhang D, Dai L, Chen Y, Dong B (2015). Waste-activated sludge fermentation for polyacrylamide biodegradation improved by anaerobic hydrolysis and key microorganisms involved in biological polyacrylamide removal. Scientific Reports, 5(1): 11675

Duan N, Dai X, Dong B, Dai L (2016). Anaerobic digestion of sludge differing in inorganic solids content: performance comparison and the effect of inorganic suspended solids content on degradation. Water Science and Technology, 74(9): 2152-2161

Duan N, Dong B, Wu B, Dai X (2012). High-solid anaerobic digestion of sewage sludge under mesophilic conditions: feasibility study. Bioresource Technology, 104: 150-156

DWA (2014). DWA Merkblatt M 368, Biologische Stabilisierung von Klérschlamm (Biological Stabilization of Sewage Sludge). Nennef, Germany: Deutsche Vereinigung fér Wasserwirtschaft, Abwasser und Abfall e.V. (in German)

Fagbohungbe M O, Dodd I C, Herbert B M J, Li H, Ricketts L, Semple K $\mathrm{T}$ (2015). High solid anaerobic digestion: Operational challenges and possibilities. Environmental Technology \& Innovation, 4: 268-284

Feng G, Liu L, Tan W (2014). Effect of thermal hydrolysis on 
rheological behavior of municipal sludge. Industrial \& Engineering Chemistry Research, 53(27): 11185-11192

Geng H, Xu Y, Zheng L, Gong H, Dai L, Dai X (2020). An overview of removing heavy metals from sewage sludge: Achievements and perspectives. Environmental Pollution, 266(Pt 2): 115375

Gerardi M H (2003). The Microbiology of Anaerobic Digesters. New Jersey: John Wiley \& Sons, Inc.

Gonzalez A, Hendriks A T W M, van Lier J B, de Kreuk M (2018). Pretreatments to enhance the biodegradability of waste activated sludge: Elucidating the rate limiting step. Biotechnology Advances, 36(5): 1434-1469

Guo H G, Zhang S T, Du L Z, Liang J F, Zhi S L, Yu J Y, Lu X B, Zhang K Q (2016). Effects of thermal-alkaline pretreatment on solubilisation and high-solid anaerobic digestion of dewatered activated sludge. BioResources, 11(1): 1280-1295

Han Y, Zhuo Y, Peng D, Yao Q, Li H, Qu Q (2017). Influence of thermal hydrolysis pretreatment on organic transformation characteristics of high solid anaerobic digestion. Bioresource Technology, 244(Pt 1): 836-843

Hidaka T, Wang F, Togari T, Uchida T, Suzuki Y (2013). Comparative performance of mesophilic and thermophilic anaerobic digestion for high-solid sewage sludge. Bioresource Technology, 149: 177-183

Higgins M J, Chen Y C, Yarosz D P, Murthy S N, Maas N A, Glindemann D, Novak J T (2006). Cycling of volatile organic sulfur compounds in anaerobically digested biosolids and its implications for odors. Water Environment Research, 78(3): 243-252

$\mathrm{Hu}$ Y, Wu J, Poncin S, Cao Z, Li Z, Li H Z (2018). Flow field investigation of high solid anaerobic digestion by Particle Image Velocimetry (PIV). Science of the Total Environment, 626: 592-602

Jahn L, Baumgartner T, Svardal K, Krampe J (2016). The influence of temperature and SRT on high-solid digestion of municipal sewage sludge. Water Science and Technology, 74(4): 836-843

Jolis D (2008). High-solids anaerobic digestion of municipal sludge pretreated by thermal hydrolysis. Water Environment Research, 80 (7): 654-662

Kapp H (1984). Schlammfaulung mit hohem Feststoffgehalt (Sludge Digestion with High-Solid Content). Band 86, Kommissionsverlag Oldenbourg, Munich, Germany: Stuttgarter Berichte zur Siedlungswasserwirtschaft (in German)

Kayhanian M (1994). Performance of a high-solids anaerobic digestion process under various ammonia concentrations. Journal of Chemical Technology and Biotechnology (Oxford, Oxfordshire), 59(4): 349352

Kirby J M (1988). Rheological characteristics of sewage sludge: A granuloviscous material. Rheologica Acta, 27(3): 326-334

Latha K, Velraj R, Shanmugam P, Sivanesan S (2019). Mixing strategies of high solids anaerobic co-digestion using food waste with sewage sludge for enhanced biogas production. Journal of Cleaner Production, 210: 388-400

Lay J J, Li Y Y, Noike T (1997). Influences of $\mathrm{pH}$ and moisture content on the methane production in high-solids sludge digestion. Water Research, 31(6): 1518-1524

Lay J J, Li Y Y, Noike T (1998). The influence of $\mathrm{pH}$ and ammonia concentration on the methane production in high-solids digestion processes. Water Environment Research, 70(5): 1075-1082

Le Hyaric R, Chardin C, Benbelkacem H, Bollon J, Bayard R, Escudié
$R$, Buffière $P$ (2011). Influence of substrate concentration and moisture content on the specific methanogenic activity of dry mesophilic municipal solid waste digestate spiked with propionate. Bioresource Technology, 102(2): 822-827

Lee E, Bittencourt P, Casimir L, Jimenez E, Wang M, Zhang Q, Ergas S J (2019). Biogas production from high solids anaerobic co-digestion of food waste, yard waste and waste activated sludge. Waste Management (New York, N.Y.), 95: 432-439

Li C, Li H, Zhang Y (2015a). Alkaline treatment of high-solids sludge and its application to anaerobic digestion. Water Science and Technology, 71(1): 67-74

Li J, Rui J, Yao M, Zhang S, Yan X, Wang Y, Yan Z, Li X (2015b). Substrate type and free ammonia determine bacterial community structure in full-scale mesophilic anaerobic digesters treating cattle or swine manure. Frontiers in Microbiology, 6: 1337

Li N, He J, Yan H, Chen S, Dai X (2017a). Pathways in bacterial and archaeal communities dictated by ammonium stress in a high solid anaerobic digester with dewatered sludge. Bioresource Technology, 241: 95-102

Li N, Xue Y, Chen S, Takahashi J, Dai L, Dai X (2017b). Methanogenic population dynamics regulated by bacterial community responses to protein-rich organic wastes in a high solid anaerobic digester. Chemical Engineering Journal, 317: 444-453

Li X, Chen L, Mei Q, Dong B, Dai X, Ding G, Zeng E Y (2018). Microplastics in sewage sludge from the wastewater treatment plants in China. Water Research, 142: 75-85

Li X, Chen S, Dong B, Dai X (2020). New insight into the effect of thermal hydrolysis on high solid sludge anaerobic digestion: Conversion pathway of volatile sulphur compounds. Chemosphere, 244: 125466

Li X, Li L, Zheng M, Fu G, Lar J (2009). Anaerobic co-digestion of cattle manure with corn stover pretreated by sodium hydroxide for efficient biogas production. Energy \& Fuels, 23(9): 4635-4639

Li Y B, Park S Y, Zhu J Y (2011). Solid-state anaerobic digestion for methane production from organic waste. Renewable \& Sustainable Energy Reviews, 15(1): 821-826

Liao N H (2016). The mechanism of total solid on concentration of hydrogen sulfide in biogas of sludge anaerobic digestion. Dissertation for Master Degree. Shanghai: Tongji University

Liao X, Li H, Cheng Y, Chen N, Li C, Yang Y (2014). Process performance of high-solids batch anaerobic digestion of sewage sludge. Environmental Technology, 35(21): 2652-2659

Liao X C, Li H (2015). Biogas production from low-organic-content sludge using a high-solids anaerobic digester with improved agitation. Applied Energy, 148: 252-259

Liao X C, Li H, Zhang Y Y, Liu C, Chen Q W (2016). Accelerated highsolids anaerobic digestion of sewage sludge using low-temperature thermal pre-treatment. International Biodeterioration \& Biodegradation, 106: 141-149

Litti Y, Nikitina A, Kovalev D, Ermoshin A, Mahajan R, Goel G, Nozhevnikova A (2019). Influence of cationic polyacrilamide flocculant on high-solids' anaerobic digestion of sewage sludge under thermophilic conditions. Environmental Technology, 40(9): 1146-1155

Liu C, Li H, Zhang Y, Liu C (2016a). Improve biogas production from low-organic-content sludge through high-solids anaerobic co-diges- 
tion with food waste. Bioresource Technology, 219: 252-260

Liu C, Li H, Zhang Y, Si D, Chen Q (2016b). Evolution of microbial community along with increasing solid concentration during highsolids anaerobic digestion of sewage sludge. Bioresource Technology, 216: 87-94

Liu J, Yu D, Zhang J, Yang M, Wang Y, Wei Y, Tong J (2016c). Rheological properties of sewage sludge during enhanced anaerobic digestion with microwave-H2O2 pretreatment. Water Research, 98: 98-108

Liu J, Zheng J, Niu Y, Zuo Z, Zhang J, Wei Y (2020a). Effect of zerovalent iron combined with carbon-based materials on the mitigation of ammonia inhibition during anaerobic digestion. Bioresource Technology, 311: 123503

Liu Z, Zhou S, Dai L, Dai X (2020b). The transformation of phosphorus fractions in high-solid sludge by anaerobic digestion combined with the high temperature thermal hydrolysis process. Bioresource Technology, 309: 123314

Lotito V, Spinosa L, Mininni G, Antonacci R (1997). The rheology of sewage sludge at different steps of treatment. Water Science and Technology, 36(11): 79-85

Luo Y L, Yang Z H, Xu Z Y, Zhou L J, Zeng G M, Huang J, Xiao Y, Wang L K (2011). Effect of trace amounts of polyacrylamide (PAM) on long-term performance of activated sludge. Journal of Hazardous Materials, 189(1-2): 69-75

Lv N, Zhao L, Wang R, Ning J, Pan X, Li C, Cai G, Zhu G (2020). Novel strategy for relieving acid accumulation by enriching syntrophic associations of syntrophic fatty acid-oxidation bacteria and $\mathrm{H}_{2} /$ formate-scavenging methanogens in anaerobic digestion. Bioresource Technology, 313: 123702

McCarty P L (2001). The development of anaerobic treatment and its future. Water Science and Technology, 44(8): 149-156

Mendes C, Esquerre K, Matos Queiroz L (2015). Application of Anaerobic Digestion Model No. 1 for simulating anaerobic mesophilic sludge digestion. Waste Management (New York, N. Y.), 35: 89-95

Moestedt J, Nilsson Påledal S, Schnürer A (2013). The effect of substrate and operational parameters on the abundance of sulphate-reducing bacteria in industrial anaerobic biogas digesters. Bioresource Technology, 132: 327-332

Mumme J, Srocke F, Heeg K, Werner M (2014). Use of biochars in anaerobic digestion. Bioresource Technology, 164: 189-197

Neumann P, Pesante S, Venegas M, Vidal G (2016). Developments in pre-treatment methods to improve anaerobic digestion of sewage sludge. Reviews in Environmental Science and Biotechnology, 15 (2): 173-211

Nges I A, Liu J (2010). Effects of solid retention time on anaerobic digestion of dewatered-sewage sludge in mesophilic and thermophilic conditions. Renewable Energy, 35(10): 2200-2206

Nguyen D, Wu Z, Shrestha S, Lee P H, Raskin L, Khanal S K (2019). Intermittent micro-aeration: New strategy to control volatile fatty acid accumulation in high organic loading anaerobic digestion. Water Research, 166: 115080

Pavlostathis S G, Giraldo-Gomez E (1991). Kinetics of anaerobic treatment: A critical review. Critical Reviews in Environmental Control, 21(5-6): 411-490

Poirier S, Madigou C, Bouchez T, Chapleur O (2017). Improving anaerobic digestion with support media: Mitigation of ammonia inhibition and effect on microbial communities. Bioresource Technology, 235: 229-239

Provenzano M R, Cavallo O, Malerba A D, Di Maria F, Cucina M, Massaccesi L, Gigliotti G (2016). Co-treatment of fruit and vegetable waste in sludge digesters: Chemical and spectroscopic investigation by fluorescence and Fourier transform infrared spectroscopy. Waste Management (New York, N.Y.), 50: 283-289

Public Works Research Institute (PWRI) (1997). Annual report of wastewater management and water quality control, No.3528. International Centre for Water Hazard and Risk Management (ISSN 0386-5878). Tokyo, Japan: Ministry of Construction (in Japanese)

Qi Y, Thapa K B, Hoadley A F A (2011). Application for filtration aids for improving sludge dewatering properties: A review. Chemical Engineering Journal, 171(2): 373-384

Rajagopal R, Massé D I, Singh G (2013). A critical review on inhibition of anaerobic digestion process by excess ammonia. Bioresource Technology, 143: 632-641

Rapport J, Zhang R, Jenkins B M, Williams R B (2008). Current anaerobic digestion technologies used for treatment of municipal organic solid waste. Sacramento: California Environmental Protection Agency

Ruiz-Hernando M, Martinez-Elorza G, Labanda J, Llorens J (2013). Dewaterability of sewage sludge by ultrasonic, thermal and chemical treatments. Chemical Engineering Journal, 230: 102-110

Sajjadi B, Raman A A A, Parthasarathy R (2016). Fluid dynamic analysis of non-Newtonian flow behavior of municipal sludge simulant in anaerobic digesters using submerged, recirculating jets. Chemical Engineering Journal, 298: 259-270

Slatter P (1997). Rheological characterisation of sludges. Water Science and Technology, 36(11): 9-18

Sommers L E, Tabatabai M A, Nelson D W (1977). Forms of sulfur in sewage sludge. Journal of Environmental Quality, 6(1): 42-46

Souza T S, Lacerda D, Aguiar L L, Martins M N C, David J A O (2020). Toxic potential of sewage sludge: Histopathological effects on soil and aquatic bioindicators. Ecological Indicators, 111: 105980

Száková J, Pulkrabová J, Černý J, Mercl F, Švarcová A, Gramblička T, Najmanová J, Tlustoš P, Balík J (2019). Selected persistent organic pollutants (POPs) in the rhizosphere of sewage sludge-treated soil: implications for the biodegradability of POPs. Archives of Agronomy and Soil Science, 65(7): 994-1009

Tang Y, Dai X, Dong B, Guo Y, Dai L (2020). Humification in extracellular polymeric substances (EPS) dominates methane release and EPS reconstruction during the sludge stabilization of high-solid anaerobic digestion. Water Research, 175: 115686

Tang Y, Li X, Dong B, Huang J, Wei Y, Dai X, Dai L (2018). Effect of aromatic repolymerization of humic acid-like fraction on digestate phytotoxicity reduction during high-solid anaerobic digestion for stabilization treatment of sewage sludge. Water Research, 143: 436444

Urrea J L, Collado S, Laca A, Díaz M (2015). Rheological behaviour of activated sludge treated by thermal hydrolysis. Journal of Water Process Engineering, 5: 153-159

Veluchamy C, Kalamdhad A S (2017). A mass diffusion model on the effect of moisture content for solid state anaerobic digestion. Journal 
of Cleaner Production, 162: 371-379

Wang F, Hidaka T, Uchida T, Tsumori J (2014). Thermophilic anaerobic digestion of sewage sludge with high solids content. Water Science and Technology, 69(9): 1949-1955

Wang T, Zhang D, Dai L, Dong B, Dai X (2018). Magnetite triggering enhanced direct interspecies electron transfer: A scavenger for the blockage of electron transfer in anaerobic digestion of high-solids sewage sludge. Environmental Science \& Technology, 52(12): 7160 7169

Wang Z W, Xu F, Manchala K R, Sun Y, Li Y (2016). Fractal-like kinetics of the solid-state anaerobic digestion. Waste Management (New York, N.Y.), 53: 55-61

Wu Z L, Lin Z, Sun Z Y, Gou M, Xia Z Y, Tang Y Q (2020). A comparative study of mesophilic and thermophilic anaerobic digestion of municipal sludge with high-solids content: Reactor performance and microbial community. Bioresource Technology, 302: 122851

Xu F Q, Li Y B, Wang Z W (2015). Mathematical modeling of solidstate anaerobic digestion. Progress in Energy and Combustion Science, 51: 49-66

Xu Y, Dai X (2020). Integrating multi-state and multi-phase treatment for anaerobic sludge digestion to enhance recovery of bio-energy. Science of the Total Environment, 698: 134196

Xu Y, Lu Y, Zheng L, Wang Z, Dai X (2020a). Perspective on enhancing the anaerobic digestion of waste activated sludge. Journal of Hazardous Materials, 389: 121847

Xu Y, Lu Y, Zheng L, Wang Z, Dai X (2020b). Effects of humic matter on the anaerobic digestion of sewage sludge: New insights from sludge structure. Chemosphere, 243: 125421

Xue Y G, Liu H J, Chen S S, Dichtl N, Dai X H, Li N (2015). Effects of thermal hydrolysis on organic matter solubilization and anaerobic digestion of high solid sludge. Chemical Engineering Journal, 264: 174-180

Yenigün O, Demirel B (2013). Ammonia inhibition in anaerobic digestion: A review. Process Biochemistry, 48(5-6): 901-911

Yin Q, Wu G (2019). Advances in direct interspecies electron transfer and conductive materials: Electron flux, organic degradation and microbial interaction. Biotechnology Advances, 37(8): 107443

Young M N, Krajmalnik-Brown R, Liu W, Doyle M L, Rittmann B E (2013). The role of anaerobic sludge recycle in improving anaerobic digester performance. Bioresource Technology, 128: 731-737

Zhang J, Xue Y, Eshtiaghi N, Dai X, Tao W, Li Z (2017). Evaluation of thermal hydrolysis efficiency of mechanically dewatered sewage sludge via rheological measurement. Water Research, 116: 34-43

Zhang Y, Feng Y, Yu Q, Xu Z, Quan X (2014). Enhanced high-solids anaerobic digestion of waste activated sludge by the addition of scrap iron. Bioresource Technology, 159: 297-304

Zhang Y, Li H, Liu C, Cheng Y (2015). Influencing mechanism of high solids concentration on anaerobic mono-digestion of sewage sludge without agitation. Frontiers of Environmental Science \& Engineering, 9(6): 1108-1116

Zhang Y Y, Li H, Cheng Y C, Liu C (2016). Influence of solids concentration on diffusion behavior in sewage sludge and its digestate. Chemical Engineering Science, 152: 674-677

Zhi S L, Zhang K Q (2019). Antibiotic residues may stimulate or suppress methane yield and microbial activity during high-solid anaerobic digestion. Chemical Engineering Journal, 359: 1303-1315

Zhou J, You X, Niu B, Yang X, Gong L, Zhou Y, Wang J, Zhang H (2020). Enhancement of methanogenic activity in anaerobic digestion of high solids sludge by nano zero-valent iron. Science of the Total Environment, 703: 135532

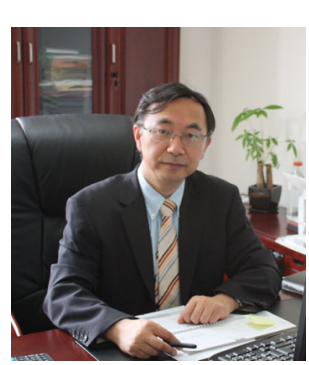

Dr. Xiaohu Dai received his B.E. and M.S. degree in Environmental Science and Engineering from Tongji University, China (1987) and Ph. D. degree from Ruhr-Universität Bochum, Germany (1992). He is currently a full professor and the Dean of College of Environmental Science and Engineering in Tongji University. His research interests mainly are on the resource utilization of organic wastes, especially sewage sludge and sewage pollutants. 